BUILDING REGIONAL CAPACITY: LESSONS FROM LEADERSHIP SOUTH WEST

Published in Education + Training, 51(8/9), 635-647.

Richard Bolden (contact author)

Lecturer

Centre for Leadership Studies

University of Exeter Business School

XfI Building

Rennes Drive

Exeter

EX4 4ST

UK

$\underline{\text { Richard.Bolden@exeter.ac.uk }}$

Tel: 01392262579

and

\title{
Jackie Bagnall
}

Teaching Fellow

University of Exeter Business School

Streatham Court

Exeter

EX4 4PU

UK 


\begin{abstract}
Purpose

In this paper the authors present their experiences and insights from an HE-led initiative to build leadership capacity within the South West of England in order to the shed light onto the processes and mechanisms of regional capacity building.

\section{Methodology/approach}

The approach was one of participative action research, whereby the authors were actively involved in the shaping and delivery of the initiative, responding to ongoing feedback and reflection. The account given within this paper is an autoethnographic case study that identifies the main phases and lessons learnt from the initiative.

\title{
$\underline{\text { Findings }}$
}

The paper identifies a number of discrete phases within the initiative, some of the challenges and how they were confronted and concludes with a set of ten principles that may help support regional capacity building initiatives for management and leadership.

\section{Originality/value}

Despite increasing emphasis on capacity building and a tendency to promote leadership as a lever for change, limited academic research has been conducted into either of these processes at a regional level. This paper seeks to contribute to both theory and practice in these areas by combining the insights of an academic and a practitioner involved in one such initiative and highlighting the underlying and emergent processes therewith.

\section{$\underline{\text { Keywords }}$}

Leadership, management, capacity building, employer engagement, higher education

\section{Type of paper}

Case study 


\section{INTRODUCTION}

Building leadership capacity across the public, private and voluntary sectors has become a fundamental objective of UK government policy (DfES, 2002). Improvements in leadership and management are regarded as a driving force in the reform of public services and central to innovation and growth in the commercial sector, yet considerable concern is expressed about the extent of the "skills gap" (DTI, 2004; CIM, 2007).

In response to calls for "better leadership", bodies such as Regional Development Agencies (RDAs), Learning and Skills Councils, Sector Skills Councils and other governmental and non-governmental bodies are increasingly working to build capacity at local and regional levels and higher education institutions (HEIs) are regarded as key facilitators in this process (Leitch, 2006). Despite this, there remains little agreement on the nature of leadership (Grint, 2005); little consensus on how best to develop it (Barker, 1997; Day, 2001); and remarkably little evidence of its impact on individual and organisational performance (Burgoyne et al., 2004). Leadership, it would seem, "is like the Abominable Snowman, whose footprints are everywhere but who is nowhere to be seen" (Bennis and Nanus, 1985: 19).

Given these very real concerns what role can universities play in regional capacity building for a concept such as leadership whilst also delivering tangible outcomes for the investment? It is this question that this paper hopes to address - to map out a form of engagement that grows critical awareness and reflection on leadership development and practice across a geographic area whilst also strengthening regional infrastructure (in terms of networks and partnerships) and delivering tangible learning outputs and products. In order to do this we will reflect on our joint experience of involvement with the Leadership South West (LSW) initiative in the South West of England from 2003 to 2006. 


\section{LEADERSHIP SOUTH WEST: A CASE STUDY IN HE- LED REGIONAL CAPACITY BUILDING}

\section{Background}

LSW is a regional initiative to increase the provision and uptake of leadership development across the South West of England. Building on from the CEML (2002) recommendations the initiative comprises two main elements (1) stimulating the level of demand and (2) improving the quality and availability of leadership development provision in the region. Central to this is the facilitation of a more aware and discerning client base for leadership development activities and the establishment of a regional infrastructure capable of supporting and delivering appropriate and desirable learning opportunities.

Following on from earlier work in the South West of England, LSW was established within the Centre for Leadership Studies (CLS) at the University of Exeter as a three year initiative. In October 2006 additional funding was secured to launch a second phase of LSW to build upon and cement the learning, outputs and networks established during Phase One. The remainder of this paper recounts the story of our engagement with Phase One of LSW and the processes through which it emerged, developed and transformed.

\section{Methodology}

In this paper, the authors (respectively the Research Fellow and Project Manager for Phase One of LSW) reflect on their experiences, learning and insights into the mechanisms of regional capacity building and the role that HE can play within this process. We will report on the range of activities engaged with, the successes and challenges encountered along the way, and the lessons and recommendations for similar and/or subsequent initiatives. In 
particular, we will focus on the development of "social capital" (considered by Adler and Kwon (2002: 17) to be "the goodwill that is engendered by the fabric of social relations and that can be mobilised to facilitate action") and reflect upon the specific issues related to employer and community engagement from an HE perspective.

Broadly our approach can be considered as an autoethnographic case study drawing on participative action research and subsequent reflection. As such, it is undoubtedly shaped by our own assumptions and experiences and may contain some post-hoc rationalisation of our actions. Despite the inherent subjectivity of this approach, however, we believe it is acceptable in this instance due to the largely emergent process through which the initiative took shape and the largely qualitative outputs derived. Furthermore, by drawing on two rather different sets of experience, with differing priorities and foci, we are able to provide a breadth of insight into different aspects of the initiative. This paper does not intend to give an objective overview of the mechanisms of HE-employer engagement, but rather to offer an insight into the thought processes and actions (some of which only became clear in retrospect) of a number of people charged with making this process a reality.

Within this paper we will take a relational view of leadership, as "a social influence process through which emergent coordination (i.e. evolving social order) and change (i.e. new values, attitudes, approaches, behaviours, ideologies, etc.) are constructed and produced" (Uhl-Bien, 2006: 668) - a property of the whole system rather than of specific individuals.

\section{Findings}

In this section of the paper we report on, what we perceived to be, the main phases of the initiative: creating connections, shaping the dialogue, growing the network, delivering 
programmes and projects (including ideas that stood still, failed or changed shape), and planning for sustainability.

\section{Creating connections}

The three year journey began with securing of the initial RDA grant. This funding, whilst sufficient to appoint a full-time Project Manager and Research Fellow, was associated with serious match funding requirements (an additional $£ 1 \mathrm{M}$ ) and delivery targets (over 13,000 learning hours). A significant factor in being able to commit to such targets was that the CLS (the academic home of LSW) had recently secured the Southwest regional franchise for the Institute of Directors (IoD) Company Direction Programme. This senior level development programme gave LSW a high-profile product from which to create learning outcomes and commercial revenues. Other learning outcomes were to be drawn from the University's modular Continuing Professional Development (CPD) programme, Masters degrees and bespoke management and leadership offerings. Being clear from the start where learning opportunities and commercial income would be coming from was fundamental in ensuring that the project remained on track and freed up space to focus on the delivery of some of the less tangible aspects of the project such as building networks and raising awareness.

LSW was launched in August 2003 with a modest amount of press coverage and moved forwards in the first instance by concentrating on the IoD programme. Recruitment to this programme gave a legitimate reason to approach to employers, with the $\mathrm{IoD}$ offering a credible commercial brand that helped alleviate concerns about being "too academic".

Our partnership with the $\mathrm{IoD}$ was strengthened through the relationship established with the newly appointed Regional Director, tasked with a major strategic review of regional 
activities. This link enabled LSW to engage directly with the IoD at a strategic level that was to the mutual benefit of both organisations. Whilst we were able to offer the IoD Regional Director support and a distinctive focus on leadership, we benefited from free mailings, magazine profiles, events and access to a significant dataset of business directors in the region. Furthermore, senior level endorsement enabled us to largely steer clear of the local conflict and competition that inevitably ensues during restructuring. As with all partnerships, the secret was the quality of relationship between individuals in the different organisations. Without mutual trust, shared objectives and a clear sense of the relative contributions of each party, such collaboration can quickly descend into competition for resources and/or territory.

Working with the IoD gave an early realisation that by partnering with a professional body with its own membership base we could reach out to a broad audience from a very small core team. A model began to emerge which focussed on the "ripple" effect - by creating strategic alliances with key regional players we could reach out to a far wider group of people. This partnering would help bring credibility by association and, at the same time, enable us to influence those agencies, professional bodies and their constituents with academicallyinformed insights, research and learning materials on leadership and management - in effect, building a virtuous cycle of knowledge exchange between HE and employers via, or in association with, intermediaries.

From this point on we focussed on building the capacity of those that supported employers across the region rather than approaching employers directly (although some direct employer contact was maintained through our various programmes). We saw our role as facilitating the emergence of a regional infrastructure for the promotion and communication of informed dialogue about leadership and leadership development. 


\section{Shaping the dialogue}

The CEML (2002) recommendations from which the LSW initiative largely arose expressed the need not only for improving the quality and availability of leadership and management provision, but also enhancing demand. From the start we were clear that in order to fulfil our role as a centre of excellence we would need to inform and shape the debate about leadership in the Southwest rather than simply providing learning opportunities. As part of a researchintensive university we recognised that this could not be achieved by being parochial or inward looking (only drawing on local evidence) but should bring the best of thinking and practice at national and international levels to the region.

Our first major opportunity to influence the debate came when we were asked to produce a defining paragraph which stated clearly the differences between management and leadership in order that regional funding bodies and stakeholders could decide how to allocate funds to projects. Concerned that agencies responsible for such large sums of money may be about to invest in poorly thought through programmes, with little awareness of the debates raging in the leadership and management literature, we decided to produce a report that laid out the arguments in a straight-forward but non simplistic manner. This report, What is Leadership? (Bolden, 2004), became the first in a series of three research reports published throughout the course of Phase One of LSW. Covering a range of issues and debates this report drew together a wide body of theory and evidence on the nature of leadership that could help the reader reach an informed awareness about the implications of their chosen approach. The report was professionally produced, carried the RDA logo, and was sent to a wide range of stakeholders across the South West (1500 copies in the first round of printing) as well as being freely available on our website. When feedback started arriving it became clear that 
this was a resource welcomed by a broad audience both within and beyond the region. When national leadership centres started requesting copies and other universities included it as course reading we realised that we really had hit upon an important way to contribute to change and development - to leverage funding from the RDA to create a resource that has impact well beyond the region but, through its association, raises the profile of the RDA, LSW, CLS and the Southwest as a whole.

LSW had (and still does) a strong learning ethos - we saw opportunities for learning in virtually everything we did and endeavoured to take our work out to the region in a way which supported and developed critical reflection. As a university-based initiative we recognised the importance of underpinning our activities with robust principles and an understanding of the mechanisms of leadership and management education. Our role was not to deliver mass vocational education but primarily to support those already offering training and development at a local level, to increase their reach, broaden their appeal and increase the rigour of what they provided. We strived to become a focal point for dialogue around the whole process of learning, programme design, the marketing and recruitment for management and leadership development - not necessarily to provide the answers but to offer a forum for debate.

As an impartial broker we were able to stand back somewhat from the activities of key agents in the region, endeavouring to identify common goals and approaches around leadership and management development. Bringing partners together can be a fruitless exercise when political objectives drive the agenda - by being apolitical we were able to become a trusted mediator and, over time, able to focus partners on what unified them - to connect with shared 
values and objectives around leadership and its contribution to the regional economy and quality of life.

Much of what we tried to do was to provoke providers within the region to reconsider how they packaged and presented their provision, and finding a means for sharing lessons and good practice. Over time LSW became a regional hub for private providers and as a hub offered an opportunity to meet with both public sector providers and those investing in programmes and development. Interestingly it was the private provider base that was most interested and engaged with our work - there is still work to do on reaching the majority of public sector provision.

\section{Growing the network}

As a small team (none of whom were directly responsible for programme delivery) it was important that LSW was able to tap into a wider network of trusted delivery agents. As a largely unregulated sector the quality of leadership and management provision varies widely between providers. The CLS Professional Network, launched in 2004, endeavoured to address this situation by offering a rigorous peer-review process for providers, ongoing professional development and networking opportunities, and an affiliation to the university. This initiative offered, in effect, a quality kitemark for providers as well as giving membership of a broad network of like-minded individuals and access to the latest theory and practice in leadership studies. Using this pool of providers we were able to influence the quality and breadth of leadership and management provision in the region, not just by regulating providers but also by maintaining a two way dialogue through which we were able to learn from successful practitioners and to use this knowledge to influence the thinking behind our own teaching and research. 
Our quarterly newsletter, Leadership Matters, became another important medium for the sharing of ideas and stories and demonstrates the importance of investing time and money to get it right. From the very beginning we were clear that if we were to start a publication it had to have the momentum to continue beyond the initial idea. We bought in specialist training for the in-house editor and have seen the publication go from strength to strength - now on its $17^{\text {th }}$ issue, with a wide contributor and subscription base.

A key feature of this publication was that it was not simply a place to recount our activities, but a forum for people and organisations across the region to share their thinking. The aim was that this regular magazine should contain articles of inherent interest and value to readers and become a reference source for leadership practitioners and decision makers. It also became a place where we could let current and potential partners promote themselves, their work and their thinking - and hence became an invaluable tool in building and maintaining relationships.

Through a combination of engagement strategies, over time the ripple effect shifted from simply being a reach out mechanism to a series of connecting relationships rather like a web. Through the creation of a web of activities, conversations and contacts we were able to expand the reach of our work and the impact of our partners. Also, through establishing a broad network of people with an interest in leadership and management we became able to attract high-profile speakers and events to the region on a financially viable business model.

\section{Delivering programmes and projects}


Alongside our networking activities and coordinating delivery of the IoD and University of Exeter programmes LSW became responsible for designing and running a number of regional leadership initiatives.

The first of these was a sector specific leadership programme commissioned by a multiagency partnership. The design incorporated, workshops, coaching and action learning sets, its methodology was blended learning and the timescale was one year. Commissioned to scope and design the programme, we went one step further and also managed to identify and secure the funding to make the project happen. Working with partners from across the relevant sector agencies we set about recruiting and delivering to 30 people from across five sub-sectors. The pilot programme was a success in terms of the cross-sector learning it created, the cross-partner working it engendered and the advocacy and energy it unleashed; so much so, that it lead to a second programme incorporating lessons learnt from the first.

Despite its ultimate success this was a challenging initiative whereby partnership and collaboration, although a prerequisite, was often associated with inertia and resistance. As people moved between roles, ideas were dropped and actions postponed - the constant flux made progress slow and frustrating and responsibility rested firmly on the shoulders of those most strongly committed to the project. Our engagement, however, gave us concrete stories to tell and allowed us to engage in dialogue from a position of experience. They also strengthened relationships with key members of the partnership and formed a strong foundation for subsequent activities.

The experience from this project gave us the track-record to shape and design subsequent funding bids, including a major European Social Fund (ESF) initiative to increase leadership 
development for women managers. This project, called "Inspire", sought to develop a variant of the IoD Director Development Programme specifically for women, with funding covering the costs of consultation, rebranding, promotional events and activities, and the recruitment of a dedicated programme coordinator. Two important lessons from this initiative included the importance of tailoring branding and promotion to the target audience and listening and being responsive to the views of participants. Through modification of the traditional IoD marketing materials (using softer colours and imagery) we managed to greatly increase the number of female managers expressing an interest in the programme. Through consultation we realised that women at this career level did not want gender-specific learning programmes but to learn alongside men in an environment reminiscent of a boardroom. As a result we used the funding to help increase female participation on the open, mixed-gender programme and invested in more carefully targeted promotion.

\section{Ideas that stood still, failed or changed shape}

In addition to the programmes and activities that succeeded there were inevitably some that were less successful and/or abandoned. The key thing about the initiatives that did work is that they are now mainstream activity of established university centres and create commercial income - the others need thinking about.

One such initiative sought to increase the uptake of leadership development for managers with disability. In a similar approach to Inspire for women, a project called "Ascend" was launched with customised promotional materials for an audience with a range of disabilities. A dedicated team member was recruited to target agencies, support groups and employers across the region and to organise a series of three events at which to open up a dialogue about the issues faced by senior managers and directors with disability. 
Despite support from the Disability Rights Commission (DRC), two of the three events were cancelled due to lack of interest and the third ran with only seven people attending. The event that did run led to some interesting conversations and the collection of important information on the barriers faced, but apart from passing that on to DRC the initiative has not progressed further. Without the ability to precisely pinpoint managers with disability and with insufficient track record in this field we failed to deliver on this contract. We drew down only $50 \%$ of the funds to cover expenses and produced a short report on our findings. Upon reflection it would seem that a project of this type needed someone conversant with the needs and issues facing those with disability and required a longer lead in time to build profile and credibility. Furthermore, it was led by a team member who was brought in especially for the project and, as such, did not connect fully with our previous learning and the broader strategic picture of LSW.

Another project which faltered and then changed direction was on educational leadership. After prolonged consultation with a range of stakeholders it was agreed that the University of Exeter, through LSW, would coordinate and deliver a range of nationally recognised leadership programmes for teachers within the South West. As with other initiatives, we began with a fact-finding exercise to see what was working well, where we could add value and how we could use the regional infrastructure to support this work.

Despite endeavours to work with openness and transparency from the start we faced suspicion and resistance from previous partners involved in the delivery of these programmes. It didn't help when we refused to give assurance that what had gone before would remain in place and, in fact, the more we looked the less we felt committed to what we 
saw. We had inherited programmes that were not financially viable and the funding that underpinned them was coming to an end. Interest in programmes was modest and without subsidy to pay for cover or time off, the possibility of recruitment was low. The tipping point came when at a conference for educational leaders the LSW Project Manager overheard three delegates expressing dissatisfaction with what had been provided to date. They were tired of rhetoric and questioned the need for programmes which espoused one set of values but the performance measures on which they were judged required a completely different set of values.

Consequently the decision was taken to close down programmes, hand back contracts and separate ourselves from those with too much vested interest in what had gone before. Unsurprisingly there was considerable bad feeling and some criticism, but we stood firm on our views about what would add value in the region and what was surplus to requirements. We would not be another programme provider spending our energy and resource marketing programmes that were neither desired nor profitable. Instead, through ongoing consultation with end-users we decided to offer an arena for professional networking and discussion. The delivery moved to the provision of a regional hub, in partnership with another HEI, from which events could be coordinated that allowed access to respected speakers and greater opportunity for open discussion between participants. Our ultimate aim was to create a network owned and championed by people engaged in educational leadership. We did not seek to be the authoritative voice but to create an environment for peer learning and exchange between those working in the field.

\section{Planning for sustainability}


As the project grew in profile, so the partnership building became easier, our influence became a trusted one. By the third year of the programme we were invited to support the strategic development of leadership for the Regional Skills Partnership (RSP). Working with senior figures from across the region, we were asked to develop a strategic framework for leadership and management development from which regional policy makers could make funding decisions.

The production of the strategic framework became the focus for the early part of 2006 and a topic of conversation between partners - the challenge being to create something that could be used by a variety of agencies across a mixed group of beneficiaries and diverse employer base. Using the LSW experience we were able to assert that there was sufficient provision in the marketplace but that this needed to be better signposted and utilised. We felt that the strategy should take into account the existing provision and be mindful of all types of learning, not just those which could be easily measured or captured. A second assertion came from the understanding that to learn is just one part of the equation, that if we want to see economic impact then that learning needs to be utilised - to be converted to action. The final part of the strategy focussed on the engagement challenge: how do we get people to realise the importance and value of leadership and management development? How do we get the messages out there to employers, managers and employees?

Thus it was that the strategic framework was based around three principles identified from consultation and feedback: learn, share and apply (Bagnall, 2006). These elements were seen as part of a dynamic cycle in which each element, and its associated activities, impacted upon the others. To create impact and produce regional cohesion all three elements needed to work 
together and be actively pursued. The model was used as a framework on which to plot the current situation and identify where additional energy and resource needed to be focussed.

Despite extensive consultation, however, the framework was initially perceived by the various agencies as "too academic" and not specific enough about actions and targets - it seemed that whilst we aimed to stimulate thoughtful debate the audience was looking for straightforward solutions. On further discussion with trusted partners we were given reassurance that this was indeed the type of document required but that we may have to take the lead in getting it accepted. It was perhaps at this point that it became clear that LSW needed to change tack. The networks and activities established to date had been largely built around personal relationships - increasingly we would need to cement our activities within more formalised agreements and take a more active political stance. It was thus that the final four months of Phase One of LSW were spent putting together a bid for Phase Two conceived as a broader regional partnership and not so closely allied to the CLS. The mainstay of Phase Two was to drive forwards the strategic framework and its principles - to support the RSP and its partners to strengthen the regional infrastructure. Fortunately the RDA saw the value of continued support for LSW and issued a second three year contract. It was at this time that the LSW Project Manager appointed a successor and stepped aside for Phase Two to be taken forward under a new style of leadership.

\section{DISCUSSION}

The account of LSW presented in this paper offers some rich insights into the processes of developing regional capacity. It is unashamedly our own story and, as such, may downplay alternative perspectives. It is without doubt that many of the successes and impacts are the result of broader collective effort yet, in this paper, we have endeavoured to draw out the key 
role that an initiative such as ours was able to play. In this section we will consolidate these insights into ten general lessons that could be applied to similar initiatives.

\section{Invest in people}

An initiative such as LSW stands or falls on the quality of its people. It was about creating a dialogue between $\mathrm{HE}$, independent providers, policy makers, employers and other stakeholders in the region and, as such, required face-to-face human contact. Whilst technical solutions such as websites and toolkits may be tempting in terms of producing tangible outcomes for the investment they are relatively poor at driving forward discussions, building relationships and establishing a shared vision. The LSW Project Manager possessed the energy, enthusiasm and experience to create such connections and whilst other solutions may now be possible we doubt they would have been effective from the outset. Furthermore, the Project Manager was careful in the people she chose to work on her team and invested considerable effort and resource in their development, thereby creating a collective expertise that endures beyond the current initiative.

\section{Create webs}

Phase One of LSW was primarily concerned with the creation of "webs" of relationships in the region. This term is chosen deliberately for a number of reasons. Webs are about connection - building a structure for communication and collaboration. They are created for a specific purpose and require the active engagement of a builder/facilitator. Webs take time to construct but are ultimately rather fragile, difficult to see and constantly changing. Likewise, when applied to leadership, webs inevitably involve some "spin" - a mechanism for the creation of sense and meaning in complex social situations (Weick, 1995). Webs, however, also hold the risk of entrapment - arguably we are all caught in webs of meaning 
that we ourselves have spun (Geertz, 1973) and with the proliferation of leadership and management initiatives both within and beyond the region there is a great danger of initiatives becoming self-serving. Where projects vie for dominance over one another partnerships can break down into competition - in remaining as apolitical as possible, it is our sense that LSW largely managed to avoid this trap and was able to bring competing organisations to the discussion table.

\section{Find trusted partners}

Key to the development of wide-ranging impact is the establishment of mutually beneficial strategic alliances. Through working with partners such as the IoD we were able to increase our reach and begin to influence decisions at regional and national-level. Such relationships need to be founded on a deep level of trust between partners, not just between organisations but between the people within them. Establishing such relationships takes time and a certain degree of luck. It requires opportunities to demonstrate credibility, competence and building a sense of legitimacy where partners feel safe to collaborate without fear of competition. When partnerships are working well, the individuals within them become more important than the organisations they represent. They also enable the development of a "bank account" of goodwill and/or reciprocal benefits that is credited and debited over time.

\section{Identify quick wins}

A publicly-funded initiative such as LSW needs to deliver on a range of agreed outputs. In order to stay on track, whilst leaving sufficient time to work on less tangible outcomes, it is important to identify the likely source of these outputs as early as possible. Once again, in the case of LSW, the IoD franchise proved invaluable and offered some quick wins both for LSW and the IoD. Furthermore, when offering leadership and management development to 
employers, some quick and tangible outcomes are helpful in building commitment and a willingness to invest in longer-term growth.

\section{Build on success}

As a relatively small initiative LSW was able to expand through building on previous successes. Initiatives such as the IoD Company Direction Programme were used as stepping stones for subsequent initiatives such as Inspire. By operating in this manner we were able to establish a track record and plan for growth organically and incrementally. In a similar vein, where initiatives were less successful we learnt from them and moved on. Over time we learnt to focus on what we were good at and to bring in additional expertise where required.

\section{Be adaptable}

The process of regional development is complex and unpredictable. Despite being only vaguely aware of this at the time, we found ourselves drawing on ideas from complexity and systems theory (e.g. Wheatley, 1995). We learnt that sometimes small inputs can lead to large impacts and vice versa. We learnt to focus our effort where it gave the greatest returns and not to persist with ideas that were proving unproductive. We learnt to change and adapt to our surroundings and the continually changing landscape of regional policy and delivery. Remaining alert to our changing context was an important factor in targeting the most significant levers for action at a particular moment in time.

\section{Challenge the status quo}

An initiative such as this inevitably confronts numerous challenges in the way HE is structured and delivered at a regional level. The Project Manager found herself working across the academic/administrative divide and straddling business, governmental and 
university cultures (what Whitchurch, 2007 refers to as a "blended professional"); the Research Fellow found himself working on projects that were in tension with traditional academic priorities; and we found ourselves delivering programmes to people who generally wanted input from practitioners rather than academic faculty. Throughout this, though, we endeavoured to take the end-user perspective - considering what could add value for them. The funding and relative autonomy of our project gave reasonable leverage to challenge restrictive university procedures but this remained subject to negotiation on a project by project basis.

\section{Embed learning}

At the heart of this initiative lay a genuine commitment to learning. Throughout we created opportunities for the two-way flow of information and understanding. We engaged in dialogue to better appreciate the practitioner perspective and endeavoured to raise the level of the debate across the region. Whilst some formalised research and evaluation was conducted and disseminated during the course of this initiative much of the learning could be conceived of as informal and permeated throughout the LSW ethos - thus, whilst not initially conceived as an "action research" project, the LSW approach was largely structured around cycles of planning, action and review. Indeed, much of what we did could be conceived of as "evaluation for knowledge" to obtain a "deeper understanding in some specific area or policy field" (Chelimsky, 1997: 100). Within this respect HEIs can act as more than knowledge repositories, becoming hubs for learning and the exchange of ideas and practice within their regions (a view echoed by Hogarth et al., 2007).

\section{Plan for succession}


It is sometimes said that the sign of a good leader is that they work themselves out of a job. Thus, one eye is always to succession and change - to ensuring the long-term viability of an enterprise without generating dependency on a single individual. This is the view that was applied to LSW - programmes were only run where financially sustainable so as to minimise dependency on external funding, and capacity was grown within the system rather than restricted to key individuals. Such a perspective is essential to ensuring sustainable regional development and it was important for LSW to "walk the talk" - to be seen to lead in the way that it espoused.

\section{Think big}

A final lesson from LSW was the importance of taking a broader view on policy, practice and thinking about leadership and management. We discovered that the region was best served through research and activities targeted at the broader national and international picture rather than focussing solely on initiatives within the South West. By taking such an approach LSW was able to establish its credentials as a world-class centre with a regional outlook and, by consequence, enhance the profile and impact of sponsors and partners as well as raising the aspirations of a provincial region.

\section{CONCLUSION}

This paper has presented the manner in which the LSW initiative achieved wide scale regional impact from a small team and limited resources. Central to this approach was a commitment to the principles of learning, sharing and applying, and an endeavour to gain influence through strategic alliances and partnerships. Initiatives such as LSW offer powerful platforms from which universities can engage with regional employers and policy makers, making a lasting impact within the region whilst also developing commercially 
viable products and programmes. Such initiatives constitute effective outreach activity that can greatly increase participation in both accredited and non-accredited HE provision and facilitate multi-directional knowledge exchange between different stakeholders within and beyond the immediate vicinity.

Fundamental to the success of such initiatives is the development of broader social networks and social capital. Whilst not readily measurable in any objective sense it argued that such capacity is inextricably linked to regional performance through raising the quality of debates and the precision of supply. Growing a discerning client base and informed policy makers is a process in which HE institutions can take an active part by becoming regional hubs and knowledge repositories. We, the authors, would advise that greater attention is given to these considerations when investing in regional capacity building and promoting employer engagement.

\section{REFERENCES}

Adler, P.S. and Kwon, S.W. (2002) Social capital: prospects for a new concept, Academy of Management Review, 21(1), 17-40.

Bagnall, J. (2006) South West Leadership \& Management Strategic Framework. Report for the Regional Strategic Partnership, Leadership South West, University of Exeter.

Barker, R.A. (1997) How can we train leaders if we do not know what leadership is? Human Relations, 50(4), 343-362.

Bennis, W. and Nanus, B. (1985) Leaders: Strategies for Taking Charge. New York: Harper and Row.

Bolden, R. (2004) What is Leadership? LSW Research Report, Centre for Leadership Studies, University of Exeter. URL: www.centres.ex.ac.uk/cls/lsw/lswreports.php 
Burgoyne, J., Hirsh, W. and Williams, S. (2004) The Development of Management and Leadership Capability and its Contribution to Performance: The evidence, the prospects and the research need. London: Department for Education and Skills.

CEML (2002) Managers and Leaders: Raising Our Game. London: Council for Excellence in Management and Leadership.

Chelimsky E (1997) Thoughts for a new Evaluation Society, Evaluation 3(1), 97-109.

CIM (2007) Institute's revised code aims to promote more effective leadership. Chartered Institute of Management press release 27/04/2007.

Day, D. (2001) Leadership development: a review in context, Leadership Quarterly, 11(4), 581-613.

DfES (2002) Government Response to the Report of the Council for Excellence in Management and Leadership. Nottingham, DfES Publications.

DTI (2004) Inspired Leadership: Insights from people who inspire exceptional performance. London: Department for Trade and Industry.

Geertz, C. (1973) The Interpretation of Cultures. New York: Basic Books.

Grint, K. (2005) Leadership: Limits and Possibilities. Basingstoke: Palgrave Macmillan.

Hogarth, T., Winterbotham, M., Hasluck, C. Carter, K., Daniel, W., Green, A. and Morrison, J. (2007) Employer and University Engagement in the Use and Development of Graduate Level Skills. Institute for Employment Research, University of Warwick on behalf of Department for Education and Skills. Research Report RR835A.

Leitch, S. (2006) Prosperity for All in the Global Economy - World Class Skills: Final Report. London: HM Treasury.

Uhl-Bien, M. (2006) Relational leadership theory: exploring the social processes of leadership and organizing, Leadership Quarterly, 17, 654-676.

Weick K. (1995) Sensemaking in Organsations. Thousand Oaks: Sage. 
Whitchurch, C. (2007) Shifting identities, blurring boundaries: the changing roles of professional managers in Higher Education. Paper presented at the Society for Research in Higher Education annual conference, Brighton, December 2007.

\section{AUTHOR BIOGRAPHIES}

Richard Bolden is a lecturer at the Centre for Leadership Studies, University of Exeter Business School. He has extensive research experience in the fields of leadership, management and education, including recent projects for the Leadership Foundation for Higher Education and HEFCE/Higher Skills Pathfinders. His research interests include distributed and shared leadership; cross-cultural leadership; leadership development; leadership in partnerships; leadership, identity and sensemaking; and leadership in Higher Education.

Jackie Bagnall joined the Centre for Leadership Studies in 2003 as project manager for Leadership South West. With a background in commercial management and organisational development she has since taken an MSc in Social and Organisational Psychology and is currently a Teaching Fellow at the University of Exeter. Her research interests are in leadership and resilience, and transformational learning. 